\title{
Molecular pathogenesis of Listeria monocytogenes in the alternative model host Galleria mellonella
}

Correspondence

Cormac G. M. Gahan

c.gahan@ucc.ie

Received 21 April 2010

Revised 9 July 2010

Accepted 3 August 2010

\author{
Susan A. Joyce ${ }^{1,2}$ and Cormac G. M. Gahan ${ }^{1,2,3}$ \\ ${ }^{1}$ Department of Microbiology, University College Cork, Cork, Ireland \\ ${ }^{2}$ Alimentary Pharmabiotic Centre, University College Cork, Cork, Ireland \\ ${ }^{3}$ School of Pharmacy, University College Cork, Cork, Ireland
}

Larvae of Galleria mellonella, the greater wax moth, provide an alternative infection model for many human pathogens as they are amenable to use at elevated incubation temperatures $\left(37{ }^{\circ} \mathrm{C}\right)$. This study and a parallel study by Mukherjee et al. [Mukherjee, K., Altincicek, B., Hain, T., Domann, E., Vilcinskas, A. \& Chakraborty, T. (2010). Appl Environ Microbiol 76, 310-317] establish this insect host as an appropriate model to investigate the pathogenesis of Listeria species. In this study we show that inoculation with Listeria monocytogenes initiates a dynamic infection in $G$. mellonella and that production of the cytolysin listeriolysin O (LLO) is necessary for toxicity and bacterial growth. Production of LLO by the non-pathogenic species Lactococcus lactis is sufficient to induce mortality in the insect model. We employed real-time bioluminescence imaging to examine the dynamics of listerial growth and virulence gene expression in the $G$. mellonella model. Analysis of lux promoter fusions demonstrated significant induction of virulence gene expression upon introduction of the pathogen into insects at both 30 and $37{ }^{\circ} \mathrm{C}$. The host response to listerial infection was examined which demonstrated that haemocyte destruction accompanies $L$. monocytogenes pathogenesis and is preceded by activation of the phenoloxidase system. Furthermore, we demonstrate that Listeria innocua is pathogenic to G. mellonella through a persistence mechanism that implicates an alternative mechanism for pathogenicity in this model.

\section{INTRODUCTION}

Listeria monocytogenes is an invasive foodborne Grampositive pathogen that causes sporadic and epidemic disease (listeriosis) that is often fatal (20-30\% case fatality rates). The pathogen has a facultative intracellular life cycle with the capacity for cellular invasion, intracellular replication and movement from cell to cell without an extracellular phase. The intracellular pathogenesis of $L$. monocytogenes is mainly attributed to the presence of a multi-gene virulence island that is regulated by the CRP/ FNR-type protein PrfA (Freitag et al., 2009; Greene \& Freitag, 2003; Sheehan et al., 1995). PrfA also regulates expression of factors required for cellular invasion (InlA and $\mathrm{InlB}$ ) and intracellular growth (Hpt) that are located elsewhere on the chromosome (Hamon et al., 2006). Virulence factors encoded on the virulence gene island include listeriolysin O (LLO, encoded by $h l y$ ), a protein that is absolutely required for phagosomal escape and

Abbreviations: AMP, antimicrobial peptide; $\mathrm{BHI}$, brain heart infusion; CFSE, carboxylfluorescein succinimydyl ester; IVIS, in vitro imaging system; LLO, listeriolysin O; PGRP-LE, peptidoglycan recognition protein; $\mathrm{PO}$, phenoloxidase; PPO, pro-phenoloxidase.

Two supplementary tables and two supplementary figures are available with the online version of this paper. pathogenesis of L. monocytogenes in mammalian models of disease (Freitag et al., 2009; Hamon et al., 2006). Also present at this locus is a gene encoding ActA, a protein required for actin polymerization and intracytoplasmic movement (Hamon et al., 2006). Clearly PrfA is essential in order to direct virulence gene expression in L. monocytogenes during the invasive and systemic phases of infection and PrfA deletion mutants are significantly attenuated in the murine model of disease (Chakraborty et al., 1992). In addition, the stress response factor SigB plays a significant role within the gastrointestinal tract and also positively regulates PrfA and other factors during adaptation to stress (Garner et al., 2006; Nadon et al., 2002). The non-pathogenic species Listeria innocua appears to have evolved from $L$. monocytogenes and lacks the virulence locus as well as specific genes (inlA, inlB, bsh and $h p t$ ) that encode virulence factors (Buchrieser et al., 2003).

Many studies have established the murine model as a useful model for analysis of the systemic phase of listerial pathogenesis (Lecuit, 2007). However, the murine model has a number of limitations including poor interaction between bacterial InlA and the cognate host receptor (Ecadherin), relatively high cost and ethical considerations associated with the analysis of mammalian hosts (Disson et al., 2008, 2009; Lecuit, 2007). Alternative model systems 
have contributed to our understanding of the infectious process of L. monocytogenes species. These include Drosophila melanogaster (Cheng \& Portnoy, 2003; Mansfield et al., 2003), Caenorhabditis elegans (Thomsen et al., 2006), Acanthamoeba polyphaga (Akya et al., 2009a) and Danio rerio embryos (Levraud et al., 2009), all of which have well-developed innate immunity but which lack adaptive immunity. Recently, D. melanogaster has contributed significantly as a model for Listeria infection revealing a Toll- and IMD-independent system, autophagy, which is induced by a long form secreted and intracellular peptidoglycan recognition protein (PGRP-LE) as a first line defence mechanism against L. monocytogenes. PGRP-LE also induces melanization and the cellular response in insects. The activity of this enzyme appears crucial for host survival in the presence of L. monocytogenes (Yano et al., 2008).

The G. mellonella insect model system has a significant advantage over other alternative models in that the larvae can be incubated at human core temperature $\left(37^{\circ} \mathrm{C}\right)$. Very recently, Mukherjee and coworkers examined larvae of $G$. mellonella and validated this species as an alternative host model for the analysis of Listeria pathogenesis (Mukherjee et al., 2010). We have concurrently performed independent experiments to determine the nature of the interaction between Listeria species and this insect model and our work extends the analysis of Listeria infection in this system. We confirm that Listeria species are pathogenic to G. mellonella. Furthermore, lux promoter fusion experiments show that virulence genes required for L. monocytogenes infection of mice are highly induced during infection of G. mellonella larvae. We also show that LLO production is a key mechanism for induction of insect mortality by L. monocytogenes and that infection of insects with a non-insect-pathogenic Lactococcus (Lact.) lactis expressing LLO is directly toxic to insects. On examining the host response we find that the phenoloxidase system mounts a response to the presence of Listeria species within $4 \mathrm{~h}$ of insect infection. Taken together, we demonstrate that pathogenesis of L. monocytogenes infection in the G. mellonella model results from high level expression of virulence genes and a dependence upon LLO for haemocyte toxicity and insect mortality.

\section{METHODS}

Maintenance of strains and cultures. Strains and plasmids utilized in this study are listed in Supplementary Table S1, available with the online version of this paper. Listeria strains were routinely cultured in brain heart infusion (BHI; Oxoid) unless otherwise stated. Escherichia coli was routinely cultured using Luria-Bertani broth and Lactococcus strains were cultured in M17 (Oxoid) media supplemented with $0.5 \%$ D-Glucose. Listeria and E. coli strains were grown with agitation at $37{ }^{\circ} \mathrm{C}$ while Lactococcus strains were cultivated at $28{ }^{\circ} \mathrm{C}$ under static conditions unless otherwise stated. Media were supplemented with the appropriate antibiotic where required; chloramphenicol $7.5 \mu \mathrm{g}$ $\mathrm{ml}^{-1}$; erythromycin $5 \mu \mathrm{g} \mathrm{ml}{ }^{-1}$. Nisin-inducible promoters required $20 \mu \mathrm{l}$ (for $10 \mathrm{ml}$ of media) of filter-sterilized nisin for induction.
Infection of G. mellonella. Overnight cultures of Listeria wild-type and mutant strains were inoculated as single colonies into $3 \mathrm{ml} \mathrm{BHI}$ and agitated at $37{ }^{\circ} \mathrm{C}$ overnight. These cultures were used to reinoculate fresh medium and allowed to proceed to exponential growth $\left(\mathrm{OD}_{600}\right.$ 0.5-0.7, unless otherwise indicated) before infection of G. mellonella larvae. E. coli and Lactococcus strains were treated in the same manner in their respective media and temperatures. Bacteria were collected by centrifugation at room temperature, rinsed with PBS then resuspended in sterile PBS to $1 \mathrm{OD}_{600}$ unit. Where required, serial dilutions were performed in sterile PBS or PBS containing the appropriate antibiotic. Insects were obtained from Livefood, UK, and stored at room temperature in the dark until use. Ten individual insects were injected with $10 \mu \mathrm{l}$ of the relevant bacterial suspension into the first right pro-leg of the second set of pro-legs using a sterile Hamilton syringe and a 30 gauge disposable needle. For gavage, the 30 gauge needle was inserted between the open insect mandibles for delivery of the dosage. All ten insects were placed in a $9.0 \mathrm{~cm}$ Petridish lined with $8.5 \mathrm{~cm}$ Whatman paper, then incubated at the appropriate temperature, usually $37^{\circ} \mathrm{C}$, in the dark. The same number of insects was injected with PBS alone and with PBS containing antibiotic where relevant. Insects were individually examined for the production of pigmentation and the time of death was recorded. Death assays performed at $37{ }^{\circ} \mathrm{C}$ were allowed to proceed for 5 days only as edycis (pupa formation) was evident at this temperature by day 6 . Bacterial suspensions were serially diluted and plated on one of BHI, LB or SW17 agar to allow the number of c.f.u. for each inoculation to be determined. Three independent replicates of each infection experiment were performed per infection strain.

Determination of bacterial numbers in G. mellonella. One hundred insects per variant (10 Petri-dishes per variant) were injected with the relevant dose of exponentially growing bacteria as described above. The initial inoculation was termed $t=0$ and was serially diluted and plated to determine the c.f.u. injected per variant. Infection was allowed to progress and at various time points $(1,2,4,5,6,20,24 \mathrm{~h})$ post-infection, five insects were removed and individually surface sterilized using $70 \%$ ethanol. Each insect was added to a $30 \mathrm{ml}$ sterile tube containing $10 \mathrm{ml}$ sterile PBS and $103 \mathrm{~mm}$ glass beads. The individual insects were crushed by vortexing for $2 \mathrm{~min}$. The mixture was serially diluted and plated onto the relevant agar medium to determine the exact number of c.f.u. present in each insect at each time point.

Real-time visualization of $L$. monocytogenes infection. $L$. monocytogenes EGDe has been chromosomally tagged with the Photorhabdus luminescens bioluminescence operon (LuxABCDE) in the absence of an upstream promoter (negative control) and in the presence of nine different promoters (Bron et al., 2006; Riedel et al., 2007, 2009). Promoters analysed represent well-characterized virulence genes of L. monocytogenes as well as the constitutive promoter $\mathrm{P}_{\text {help }}$; EGDe::luxP $\mathrm{P}_{\text {help }}$ was used as a positive control (see Supplementary Table S1). This promoter fusion was also applied to L. innocua strain Clip 11262 to allow detection of infection by either Listeria species under different infection and temperature conditions. Each of the ten bioluminescent-tagged strains was grown for injection as described above. Ten individual insects were injected with each variant $\left(\mathrm{OD}_{600} 0.1\right)$ and placed in duplicate on $4.0 \mathrm{~cm}$ Petri-dishes. The insects were incubated at $37{ }^{\circ} \mathrm{C}$ in the chamber of an in vitro imaging system (IVIS-100). Bioluminescence levels (490 nm) were recorded at $30 \mathrm{~min}$ intervals for $1 \mathrm{~min}$ over a $24 \mathrm{~h}$ time period. Light production was quantified using the Living Image programme (Xenogen) from each Petri-dish and therefore from each of the different promoters over the time-course of an infection in $G$. mellonella. Experiments were repeated three times independently.

Phenoloxidase (PO) activity. Insects were infected as described above. At different time points during the infectious process, insects 
were chilled on ice for 15 min, surface sterilized with $70 \%$ ethanol and then dissected to collect the insect haemolymph to a pre-chilled Eppendorf containing the same volume of Graces insect media (GIM). The plasma was isolated following centrifugation of the mixture at 14000 r.p.m. for $10 \mathrm{~min}$ at $4{ }^{\circ} \mathrm{C}$ and retained on ice. The PO activity in the haemolymph plasma of final instar (last moult) G. mellonella larvae was quantified by using a microplate enzyme assay as described by Eleftherianos et al. (2006). Briefly, a reaction mixture containing $115 \mu \mathrm{l} 50 \mathrm{mM}$ PBS buffer ( $\mathrm{pH}$ 6.5), $10 \mu \mathrm{l}$ diluted haemolymph plasma, $2 \mu \mathrm{l}$ E. coli LPS ( $5 \mathrm{mg} \mathrm{ml}^{-1}$, in control reactions only) (Sigma) was left for $1 \mathrm{~h}$ on a shaker at slow speed (1 r.p.m.), at room temperature, to allow the activation of the enzyme; the reaction was started by adding $25 \mu \mathrm{l} 20 \mathrm{mM} 4$-methyl catechol (Sigma). The change in absorbance was read at $490 \mathrm{~nm}$ for $1 \mathrm{~h}$ at room temperature with a reading taken every $1 \mathrm{~min}$. Three insects were used per treatment and the experiment was repeated three times.

Haemocyte viability. At $24 \mathrm{~h}$ post-infection, larvae were chilled, surface sterilized and bled into pre-chilled GIM and the cell density was adjusted accordingly to $5 \times 10^{6} \mathrm{ml}^{-1}$. Cells were washed three times with GIM and trypan blue $(0.02 \%$ in PBS) stained for $10 \mathrm{~min}$ at room temperature, washed three times with PBS and then fixed with $4.0 \%$ paraformaldehyde in PBS. Trypan-blue-stained and total cell counts were visualized and recorded with a light microscope at $\times 200$ magnification using a haemocytometer and a Countess Cell Counter (Invitrogen).

Confocal imaging of Listeria infection of insect haemocytes. Differential labelling of Listeria species allows the distinctive detection of intracellular and surface-bound bacteria. Carboxylfluorescein succinimydyl ester (CFSE) attaches to bacterial cells by forming stable conjugates with aliphatic amines (Karrer et al., 1992) to monitor the Gram-positive bacterial population. In order to distinguish between internalized and extracellular bacterial cells the bacterial population was labelled with CFSE, then linked with biotin before injection into G. mellonella. Briefly, overnight culture $\left(\mathrm{OD}_{600}\right.$ 2) was pelleted then washed twice in PBS, then incubated with CFSE for $15 \mathrm{~min}$ in the dark and washed three times in PBS. The cells were biotinylated by addition of No-Weigh Sulpho-NHS-Biotin (Pierce Scientific), incubated at room temperature for $40 \mathrm{~min}$ and washed three times with PBS. Approximately $10 \mu \mathrm{l}$ of each treated culture $\left(\mathrm{OD}_{600} 1\right)$ was injected into each of 10 insects as described above. Infection was continued to the following time points: $1,2,4,7,24 \mathrm{~h}$ post-infection. At the different time points, an average of five insects were bled (as described above) and $200 \mu$ lof the total haemolymph was added to an L-lysine-coated slide and incubated at $4{ }^{\circ} \mathrm{C}$ for $30 \mathrm{~min}$. Unattached cells were washed from the slides with PBS and cells were fixed in formalin/formaldehyde $(10.0 \% / 4.0 \%$, Sigma) for $20 \mathrm{~min}$ at room temperature and washed again. Bound cells were treated with streptavidin-allophycocyanin (Pierce) for $30 \mathrm{~min}$ at $4{ }^{\circ} \mathrm{C}$. Cells were permeabilized by addition of $0.2 \%$ Triton X-100 (Sigma) for $5 \mathrm{~min}$ then washed with PBS. The slides were mounted using fluorescent mounting media (DakoCytomation) and allowed to dry. Cells were visualized by confocal microscopy at the following wavelengths: $488 \mathrm{~nm}$ for CFSE (Fig. 6), 543-550 nm for rhodaminephalloidin (actin), which stained any region producing actin, and $543-550 \mathrm{~nm}$ for streptavidin-allophycocyanin to detect non-internalized cells.

RNA extraction and RT-PCR. Approximately $7 \mathrm{~h}$ after infection with Listeria, insects were chilled on ice for $15 \mathrm{~min}$, surface sterilized with $70 \%$ ethanol and then dissected to collect the fat body tissue. Fat bodies from three individual insects were pooled $(100 \mathrm{mg})$. To isolate total RNA, extracted tissues were homogenized in TRI reagent (Sigma). Single-step RT-PCR was performed using the 'OneStep' RTPCR kit (Qiagen). Each reaction was carried out in a $50 \mu$ l volume containing $0.6 \mathrm{pM}$ of forward and reverse gene primers and $2 \mu \mathrm{g}$ of
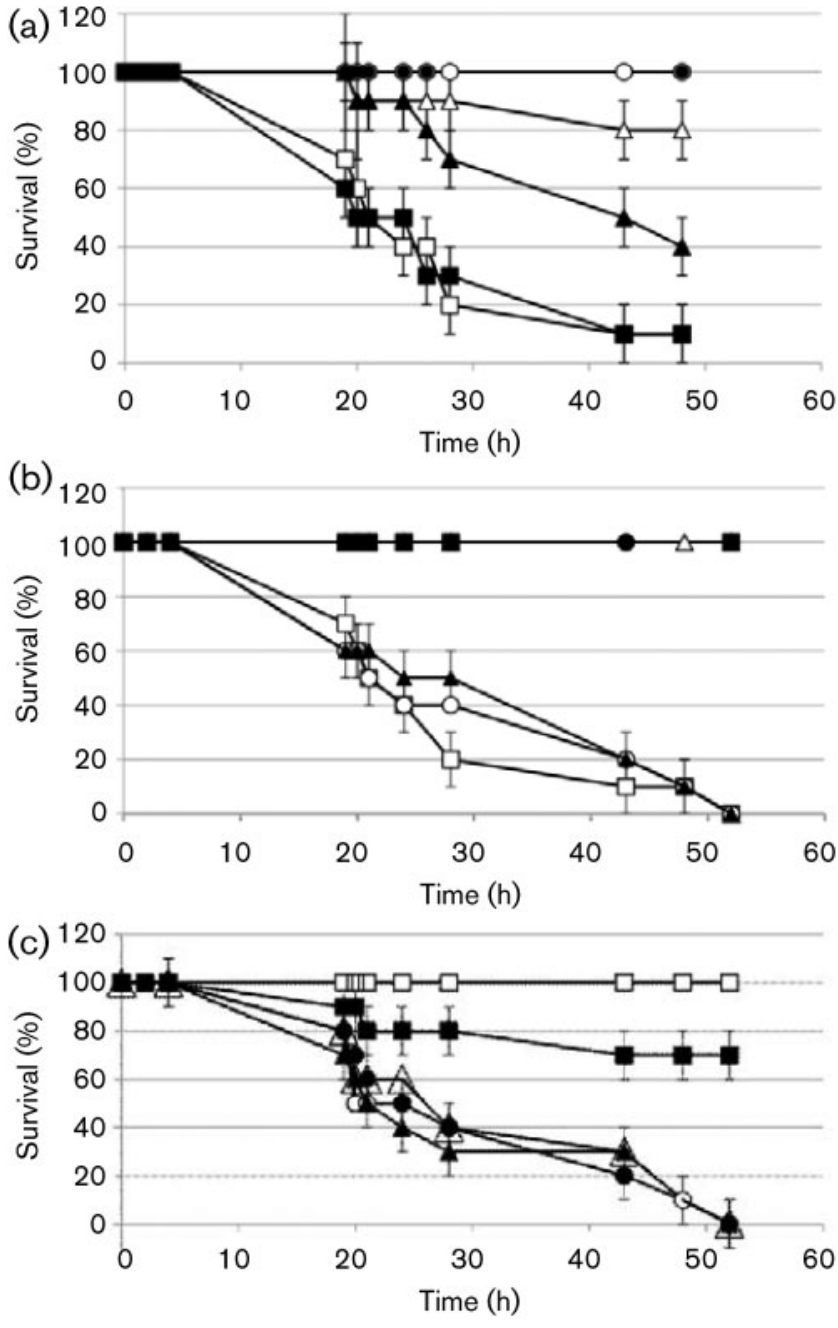

Fig. 1. Listeria species are pathogenic to G. mellonella. (a) The lethal dose of $L$. monocytogenes (filled symbols) and $L$. innocua (open symbols) required to kill $50 \%$ of $\mathrm{G}$. mellonella insects $\left(L D_{50}\right)$ corresponds to 300000 c.f.u. delivered in $10 \mu \mathrm{l}$ for $L$. monocytogenes EGDe and 420000 c.f.u. for L. innocua species. Squares, $1 \times 10^{-2}$; triangles, $1 \times 10^{-3}$; circles, $1 \times 10^{-4}$. (b) $\mathrm{L}$. monocytogenes EGDe:: $\operatorname{luxP}_{\text {help }}(\boldsymbol{\Delta})$ is equally as pathogenic as EGDe wild-type strain to G. mellonella; L. innocua F4 $(O)$ is pathogenic to $G$. mellonella at the same dose, while Bifidobacterium breve $(\triangle)$ and Lact. lactis $(\square)$ are avirulent to the insect. $\square$, L. innocua CLIP 11262; •, PBS control. (c) $L$. monocytogenes EGDe mutated in prfA ( $\square$ ) or hly ( $\square$ ) is attenuated in $G$. mellonella, while mutants in $\operatorname{act} A(\boldsymbol{\Delta})$ and $\operatorname{sig} B$ (๑) have no effect on virulence in this model. $\bigcirc$ and $\triangle, L$. monocytogenes EGDe wild-type. For $(\mathrm{a}-\mathrm{c}), n=10$ per data point and error bars represent SD. Experiments were replicated three times independently and a representative experiment is shown.

RNA template. All primers were gene-specific (Supplementary Table S2). Reverse transcription was allowed to proceed for $30 \mathrm{~min}$ at $50{ }^{\circ} \mathrm{C}$, reverse transcriptases were inactivated and DNA polymerase was activated by incubation for $15 \mathrm{~min}$ at $95{ }^{\circ} \mathrm{C}$. Amplifications were performed on a PTC-100 thermal controller (MJ Research) under the 
following cycling conditions: $1 \mathrm{~min}$ at $94{ }^{\circ} \mathrm{C}, 1 \mathrm{~min}$ at $55{ }^{\circ} \mathrm{C}$ and $1 \mathrm{~min}$ at $72{ }^{\circ} \mathrm{C}$ for 35 cycles. RT-PCR control reactions for actin protein were performed as described by Bergin et al. (2006). Reactions were assessed by $1.0 \%$ agarose gel electrophoresis $\left(90 \mathrm{~V} \mathrm{~cm}^{-1}\right)$ in TAE and visualized by ethidium bromide staining.

\section{RESULTS}

\section{Establishing G. mellonella as a model system for analysis of Listeria infection}

In order to determine if G. mellonella could be used as an infection model for Listeria infection, the human pathogenic species L. monocytogenes EGDe (serotype 1/2a) and the non-human pathogenic L. innocua Clip 11262 were used to infect insects. In initial dose-response experiments, Listeria species were serially diluted then injected into each of 10 individual insects and monitored for the time taken to kill $50 \%$ of insects $\left(\mathrm{LT}_{50}\right)$ by each dose over a $48 \mathrm{~h}$ period at $37{ }^{\circ} \mathrm{C}$ (Fig. 1a-c). Both L. monocytogenes and $L$. innocua species reproducibly killed $100 \%$ of insects within $48 \mathrm{~h}$ at $37^{\circ} \mathrm{C}$ (Fig. 1a) with the highest doses at $10^{7}$ c.f.u. per $\mathrm{OD}_{600}$ unit per $\mathrm{ml}$ and $10^{6}$ c.f.u. per $\mathrm{OD}_{600}$ unit per $\mathrm{ml}$, respectively. The exact $\mathrm{LT}_{50}$ for both of these strains was recorded as $22 \pm 1 \mathrm{~h}$ at these dosages. Below this threshold, with $10^{5}$ c.f.u., L. innocua was lethal to only $20 \%$ of the insect larvae over $50 \mathrm{~h}$ while an $\mathrm{LT}_{50}$ of $43 \mathrm{~h}$ was recorded for L. monocytogenes. More specifically, $3 \times 10^{5}$ c.f.u. and $4.2 \times 10^{5}$ c.f.u. L. monocytogenes strain EGDe and $L$. innocua, respectively, were required to kill $50-100 \%$ of insects within $24 \mathrm{~h}$ at $37^{\circ} \mathrm{C}$ (Fig. 1b).

L. monocytogenes mutated in specific virulence genes has previously been analysed using other model systems (Levraud et al., 2009; Mansfield et al., 2003; Thomsen et al., 2006). In order to examine the efficacy of G. mellonella larvae as a model system for Listeria infection, we examined the infectivity of LO28 and EGDe strains that are mutated for known virulence genes (Fig. 1c and Table 1). In all cases, the $\mathrm{LT}_{50}$ at $37{ }^{\circ} \mathrm{C}$ was recorded where G. mellonella insects were injected with the lowest possible wild-type killing dose $\left(3 \times 10^{5}\right.$ c.f.u. $)$ for each variant. Here, the wildtype strain and mutants in act $A$, inl $A B$ and sigB elicited an $\mathrm{LT}_{50}$ of $21-25 \mathrm{~h}$ and were therefore equally as virulent as the wild-type parent in the insect model. A delay of $101 \mathrm{~h}$ (greater than 4 days) was evident for mutants in PrfA indicating significant attenuation in this model. Strains mutated in haemolysin (LLO) production were completely attenuated for virulence; these strains did not lead to mortality in any insect in any of three replicates. Comparative $\mathrm{LT}_{50}$ was also calculated for other $L$. monocytogenes strains with mutations in hly and prfA (Table 1). L. monocytogenes LO28 (serotype 1/2c), F2365 (serotype $4 \mathrm{~b}$ ) and EGDe (serotype 1/2a) wild-type strains showed similar $\mathrm{LT}_{50}$ values of $21-25 \mathrm{~h}$ on injection of equivalent c.f.u. values. However, the $\mathrm{LT}_{50}$ value calculated for the F2365 PrfA mutant was 46-48 h, which was twofold slower than the wild-type parent strain but 2.5 -fold faster than a PrfA mutant in strain EGDe. An $\mathrm{LLO}^{-}$strain of $L$. monocytogenes F2365 $(\Delta h l y)$ was completely attenuated in G. mellonella. L. monocytogenes strain F2365 mutated in sigB demonstrated no attenuation in this model system. Finally, non-pathogenic commensal bacteria, Bifidobacterium breve UCC2003, Lact. lactis NZ9000 and E. coli EC101 were non-pathogenic to G. mellonella; no larvae were killed 5 days post-injection (Table 1).

\section{Temperature affects Listeria infection of G. mellonella}

The G. mellonella insect model system has the advantage of being amenable to a broad range of incubation temperatures following infection. It has been well documented that many of the known virulence genes in L. monocytogenes exhibit temperature-dependent expression (McGann et al., 2007; Peel et al., 1988). In order to determine whether such effects could be determined in the G. mellonella insect model system, 10 individual insects were infected with one of $L$. innocua, L. monocytogenes EGDe or with $L$. monocytogenes mutant strains as described above, and then monitored hourly during incubation at 30 and $37{ }^{\circ} \mathrm{C}$. The mutants chosen were of two types (i) temperaturedependent genes that require elevated temperatures for optimal expression in vitro: $h l y, \operatorname{prf} A, \operatorname{sig} B$, inlAB; and (ii) temperature-dependent genes that require lower temperatures for expression: cheA and fliA. L. monocytogenes was capable of causing insect death at both temperatures,

Table 1. $L T_{50}$ of G. mellonella at 30 and $37^{\circ} \mathrm{C}$ when injected with $10 \mu \mathrm{l}$ of exponentially growing cells $\left(\mathrm{OD}_{600} 0.1\right)$ for different strains

Experiments were performed in triplicate; values shown are mean \pm SD. ND, Not done.

\begin{tabular}{|c|c|c|}
\hline Bacterial strain & $\mathbf{L T}_{50}(\mathrm{~h})$ at $37^{\circ} \mathrm{C}$ & $\mathrm{LT}_{50}(\mathrm{~h})$ at $30{ }^{\circ} \mathrm{C}$ \\
\hline L. monocytogenes EGDe & $23 \pm 3$ & $29 \pm 3$ \\
\hline EGDe $\Delta i n l A$ & $23 \pm 2$ & $32 \pm 3$ \\
\hline $\mathrm{EGDe} \Delta \operatorname{sig} B$ & $23 \pm 2$ & $28 \pm 2$ \\
\hline EGDe $\Delta a c t A$ & $23 \pm 2$ & $32 \pm 2$ \\
\hline $\mathrm{EGDe} \Delta f u r$ & $23 \pm 3$ & $\mathrm{ND}$ \\
\hline $\mathrm{EGDe} \Delta p r f A$ & $124 \pm 7$ & No death \\
\hline $\mathrm{EGDe} \Delta h l y$ & No death & No death \\
\hline EGDe $\Delta$ cheA & $36 \pm 5$ & $32 \pm 2$ \\
\hline $\mathrm{EGDe} \Delta f l i A$ & $36 \pm 5$ & $48 \pm 3$ \\
\hline L. monocytogenes F2365 & $22 \pm 3$ & $\mathrm{ND}$ \\
\hline $\mathrm{F} 2365 \Delta \operatorname{sig} B$ & $22 \pm 2$ & ND \\
\hline $\mathrm{F} 2365 \Delta h l y$ & No death & ND \\
\hline $\mathrm{F} 2365 \Delta p r f A$ & $48 \pm 3$ & ND \\
\hline L. monocytogenes LO28 & $21 \pm 3$ & ND \\
\hline L. innocua Clip 11262 & $23 \pm 2$ & $22 \pm 1$ \\
\hline L. innocua $\mathrm{F} 4$ & $23 \pm 3$ & $32 \pm 2$ \\
\hline B. breve UCC2003 & No death & ND \\
\hline Lact. lactis NZ9000 & No death & $\mathrm{ND}$ \\
\hline E. coli $\mathrm{DH} 10 \mathrm{~B}$ & No death & $\mathrm{ND}$ \\
\hline
\end{tabular}


although a $5-7 \mathrm{~h}$ delay in mortality was evident at $30{ }^{\circ} \mathrm{C}$ (Table 1). Infection of larvae with an L. monocytogenes mutant in prfA incubated at $30{ }^{\circ} \mathrm{C}$ did not result in insect mortality even after 5 days, while at $37^{\circ} \mathrm{C}$ this mutant showed an $\mathrm{LT}_{50}$ of $124 \mathrm{~h}$. Strains with mutations in inlA and inlB showed no difference in $\mathrm{LT}_{50}$ at 30 and $37^{\circ} \mathrm{C}$ and mirrored wild-type infections at these temperatures. $L$. monocytogenes EGDe strains mutated in either cheA or fliA were equally as pathogenic as G. mellonella at $37^{\circ} \mathrm{C}$, although a delay of 10-13 h was evident when compared with the wild-type strain. A differential effect was clear when the $\mathrm{LT}_{50}$ of these mutants was examined at $30{ }^{\circ} \mathrm{C}$. Here, the cheA mutant was equally as pathogenic as the wild-type strain $\left(\mathrm{LT}_{50}\right.$ of $\left.32 \mathrm{~h}\right)$ to the insect larvae while the $\mathrm{LT}_{50}$ of the fliA mutant increased to $48 \mathrm{~h}$, indicating that the presence of flagella plays a role in pathogenicity at $30{ }^{\circ} \mathrm{C}$. L. monocytogenes is motile at temperatures below $30{ }^{\circ} \mathrm{C}$. Taken together, these data implicate a role for temperature in the resolution of virulence of Listeria species during infection of G. mellonella larvae and suggest an optimal temperature for L. monocytogenes pathogenesis of $37^{\circ} \mathrm{C}$ in this model system.

\section{L. monocytogenes infection of G. mellonella is accompanied by bacterial growth}

We utilized bioluminescent L. monocytogenes (Riedel et al., 2007, 2009) to monitor growth in the insect. Our data represent a summary of three independent experiments. We have shown that $L$. monocytogenes $\mathrm{EGDe}: \operatorname{luxP}_{\text {help }}$ (Luxtagged strain) is equally as pathogenic as the wild-type is to G. mellonella insects (Fig. 1b). Similarly survival of insects in the model is identical following infection with the Luxtagged $L$. innocua: : luxPhelp strain as with the wild-type $L$. innocua strain (data not shown). Following infection with Lux-tagged Listeria, luminescence was clearly detectable using the Xenogen IVIS system (Fig. 2a). L. monocytogenes EGDe:: $\operatorname{lux} \mathrm{P}_{\text {help }}$ and L. innocua $11262:$ : luxP $\mathrm{P}_{\text {help }}$ were used to infect insects by either injection or oral gavage (Fig. 2b). During the first $2 \mathrm{~h}$ after infection, the level of bioluminescence decreased rapidly for both strains irrespective of the means of infection. For the injected L. monocytogenes, an increase in light emission was seen at $4 \mathrm{~h}$ post-infection that persisted for $10 \mathrm{~h}$ before reaching a basal level until death of the insects. Death of the insects coincided with an increase in the relative luminescence. L. innocua also demonstrated a twofold increase in light levels between 15 and $35 \mathrm{~h}$ post-infection. In contrast, gavaged $L$. monocytogenes EGDe:: luxP $\mathrm{P}_{\text {help }}$ and L. innocua 11262::luxP help both showed decreasing light production throughout the course of infection.

In order to confirm the growth kinetics of L. monocytogenes and L. innocua in G. mellonella, insects were crushed and the bacteria were harvested and quantified. Analysis of bacterial numbers confirmed that wild-type L. monocytogenes numbers decreased for the first $2 \mathrm{~h}$ post-injection, with a rapid increase in bacterial numbers thereafter (Fig. 2c). For $L$. innocua, c.f.u. counts also fell significantly within the first $2 \mathrm{~h}$ post-infection but rapid growth was never achieved, rather the bacteria persisted in the insect until death. We also examined the growth of the $L$. monocytogenes mutant variants deleted in sigB, actA, prfA and hly (Fig. 2d). Mutants were reduced following initial inoculation and failed to recover to the same levels as the wild-type over the course of the infection with only the hly (LLO) mutant appearing completely defective for growth. The data indicate that specific mutations affect the capacity for L. monocytogenes to grow in the insect host but that mortality is not directly related to only bacterial numbers in vivo.

\section{Haemolysin production is critical to L. monocytogenes pathogenesis in G. mellonella}

The fact that mutants in haemolysin production were completely attenuated in this model system (Table 1) suggests that haemolysin (LLO) is a dominant factor for $L$. monocytogenes pathogenicity in this insect model. In order to determine if the presence of this cytolysin alone is sufficient to cause insect death, the non-insect-pathogenic Lact. lactis strain NZ9000 (Fig. 1c and Table 1) was used to deliver LLO to G. mellonella insects. Lact. lactis containing a plasmid either expressing LLO constitutively (pQE30/hly) or expressing LLO under the control of a nisin-inducible promoter (pNZ8048) was injected into G. mellonella larvae and insect death was monitored as described above. At the highest dose $\left(\mathrm{OD}_{600} 0.1\right)$, strains either that constitutively expressed LLO or where expression was pre-induced by addition of nisin caused insect death 3 days post-infection (Fig. 3a) with up to $70 \%$ of insects killed by 4 days postinfection. An $\mathrm{LT}_{50}$ of $73 \mathrm{~h}$ was recorded following infection at $37{ }^{\circ} \mathrm{C}$. Control inoculants (Lact. lactis with empty vector, Lact. lactis carrying LLO in pNZ8048 without nisin induction, PBS containing nisin and/or antibiotic) had no effect on G. mellonella mortality. The growth of Lact. lactis expressing LLO was examined over time in the insect host, as described above (Fig. 3b). Within $2 \mathrm{~h}$ post-infection, all of the Lact. lactis strains had decreased in number from $1 \times 10^{8}$ c.f.u. to $2 \times 10^{3}$ c.f.u. and they persisted at this level irrespective of the presence of haemolysin. Haemocyte viability was then examined (Fig. 3c). Here, haemocyte viability decreased to $60 \%$ compared with control PBS injection in the presence of wild-type Lact. lactis, which could indicate haemocyte migration to the insect fat body (primitive liver). However, the presence of LLO further reduced this level to between 30 and $40 \%$. Taken together, these data indicate that haemolysin production alone is sufficient to cause insect death within $72 \mathrm{~h}$ when expressed in high-density infections and that its presence does not confer any growth advantage on Lact. lactis in this model.

\section{In vivo monitoring of $L$. monocytogenes virulence gene expression during G. mellonella infection}

Virulence factors in L. monocytogenes are expressed at low levels during growth in laboratory medium but are 
(a)
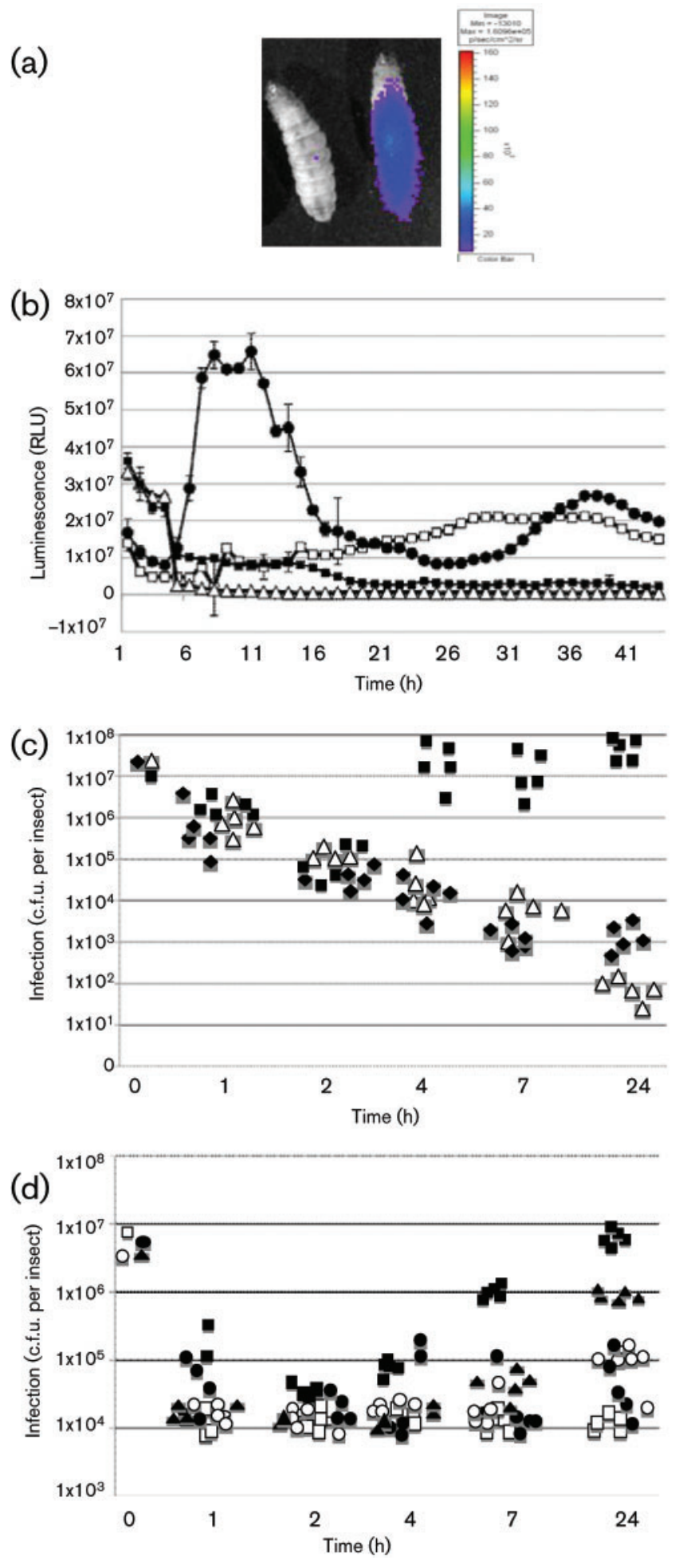

transcriptionally induced within host cells or during murine infection (Bubert et al., 1999; Camejo et al., 2009; Ermolaeva et al., 2004; Riedel et al., 2009; Wilson et al., 2001). We investigated whether L. monocytogenes infection in the insect model induces similar levels of virulence gene expression upon entry into the insect host. We utilized
Fig. 2. Growth of injected and gavaged L. monocytogenes EGDe:: luxP $P_{\text {help }}$ and injected and gavaged L. innocua 11262 EGDe: : luxP help in G. mellonella. (a) In vivo luminescence imaging was used to analyse host-pathogen interactions in the insect host. G. mellonella were injected with PBS and L. monocytogenes EGDe : : luxP $P_{\text {help }}$ and visualized using IVIS at $1 \mathrm{~h}$ post-infection. (b) Emission of light using Xenogen IVIS at $37{ }^{\circ} \mathrm{C}$ over $42 \mathrm{~h}$ representing the growth of injected and gavaged $L$. monocytogenes EGDe : : luxP $P_{\text {help }}(\boldsymbol{O}$ and $\boldsymbol{\square}$, respectively) and injected and gavaged L. innocua 11262 EGDe: : luxP help $(\square$ and $\triangle$, respectively) in $G$. mellonella. Ten individual insects were monitored per infection. Experiments were performed three times independently and a single experiment is presented. Error bars, SEM. (c, d) Insects were infected via injection and bacterial growth was monitored over time by homogenization of five individual insects per treatment at each time point and subsequent plate counting. (c) $\mathbf{\square}$, L. monocytogenes EGDe : : luxP $\mathrm{P}_{\text {help }} ;$, , L. innocua 11262 EGDe : : luxP help; $\triangle$, E. coli. (d) $\boldsymbol{\square}$, L. monocytogenes EGDe; mutant strains: $\bullet$, prfA; $\mathbf{\Delta}$, sigB; $\square$, hly; $\bigcirc, \operatorname{act} A$.

chromosomally integrated promoter fusions to a lux reporter system to monitor expression from virulence gene promoters in L. monocytogenes strain EGDe (see Supplementary Table S1) during infection of G. mellonella larvae at $37{ }^{\circ} \mathrm{C}$ (Fig. 4a and b). Control strains contained either no promoter (negative control) or the constitutive $\mathrm{P}_{\text {help }}$ promoter (positive control) (Riedel et al., 2007, 2009) and insects were monitored every $30 \mathrm{~min}$ over $22 \mathrm{~h}$ for the production of light in a temperature-controlled enclosed IVIS. We detected significant activity from a number of promoters resulting in luminescence in the insect model. Prior to infection of insects, activity from the $\mathrm{P}_{\text {hly }}$ promoter was undetectable. However, within $30 \mathrm{~min}$ of infection, activity from the $\mathrm{P}_{h l y}$ promoter was clearly detectable, reaching a peak of $8.5 \times 10^{7}$ RLU at $7 \mathrm{~h}$ post-infection. This activity was twofold higher than the maximum recorded for the constitutive $\mathrm{P}_{\text {help }}$ promoter. $\mathrm{P}_{p r f A}, \mathrm{P}_{m p l}$, $\mathrm{P}_{a c t A}$ and $\mathrm{P}_{\text {plcA }}$ promoters were also activated during infection of the insect. However, $\mathrm{P}_{h l y}$ was the most highly expressed promoter during insect infections. No light detection was evident from the $\mathrm{P}_{h p t}, \mathrm{P}_{\text {inlA }}$ or $\mathrm{P}_{\mathrm{p} 60}$ promoter constructs or the negative control (no promoter). These data indicate that many of the key L. monocytogenes virulence genes are significantly induced in the G. mellonella insect model at $37{ }^{\circ} \mathrm{C}$.

When these experiments were replicated at $30{ }^{\circ} \mathrm{C}$ (Fig. $4 \mathrm{c}$ and d), no detectable activity was evident for the $\mathrm{P}_{p r f A}, \mathrm{P}_{h p t}, \mathrm{P}_{\text {inlA }}$ and $\mathrm{P}_{\mathrm{p} 60}$ promoter fusion strains. Whilst significant expression of $\mathrm{P}_{h l y}$ was detected during insect infection at $30{ }^{\circ} \mathrm{C}$, levels were lower than those seen during infection at $37{ }^{\circ} \mathrm{C}$. Taken together, these data demonstrate strong induction of expression of specific virulence genes in L. monocytogenes during infection of the insect host at both 37 and $30{ }^{\circ} \mathrm{C}$.

\section{G. mellonella response to infection by Listeria species}

We have shown that L. monocytogenes infects and kills $G$. mellonella insect larvae using many of the genetic factors 

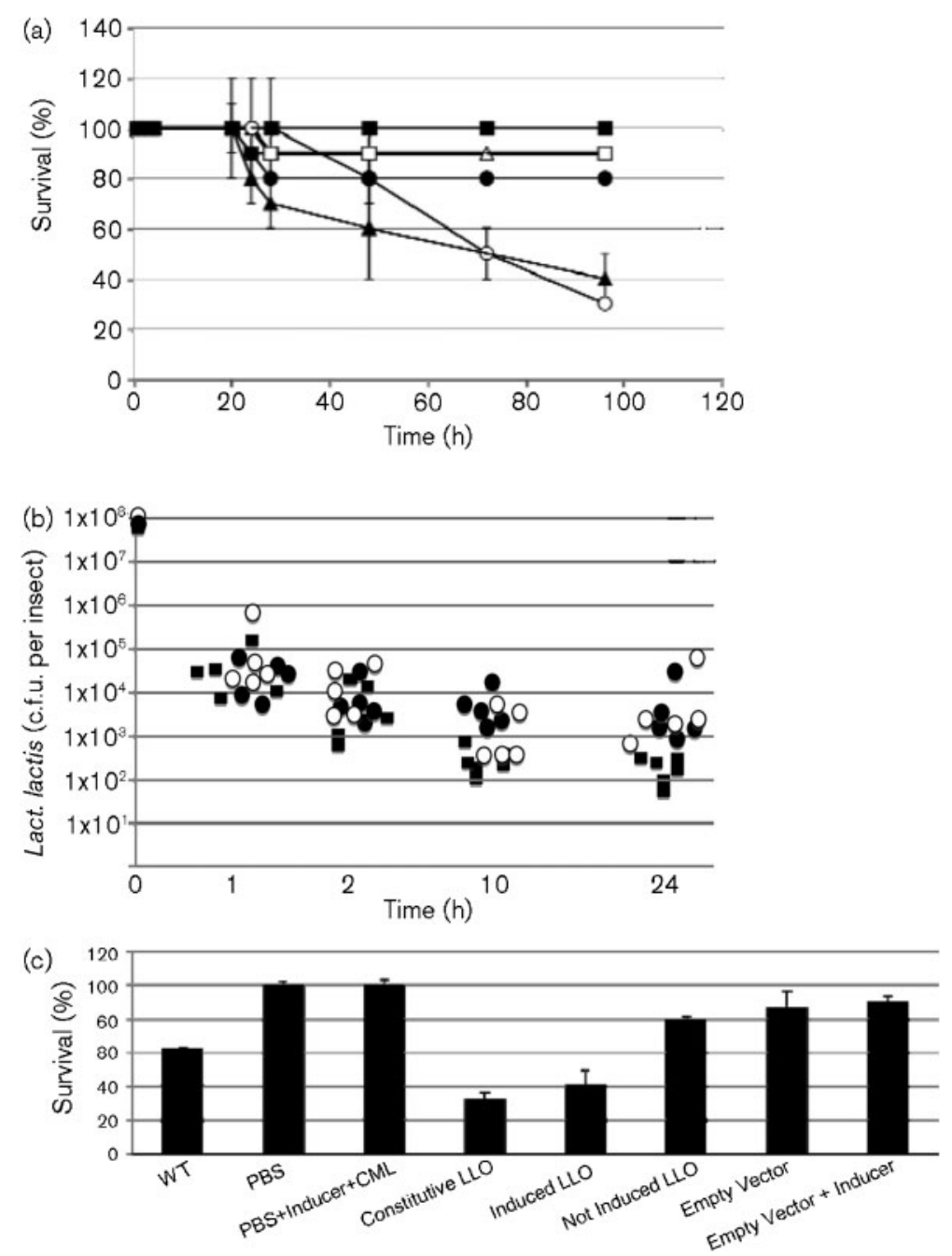

Fig. 3. The production of haemolysin is sufficient to induce G. mellonella insect mortality when produced using an engineered Lact. lactis strain. (a) Fifty per cent of insects were killed $72 \mathrm{~h}$ after infection with Lact. lactis producing haemolysin. An equivalent amount $\left(O D_{600} 0.1\right)$ of each variant was injected into each of ten insects in the presence or absence of antibiotic and/or nisin to induce LLO production. $\mathbf{\Delta}$, Lact. lactis LLO-induced; $\mathbf{0}$ Lact. lactis LLO-non-induced. Controls were the empty vector $(\square)$, Lact. lactis with no vector $(\triangle)$, Lact. lactis constitutively expressing LLO $(\bigcirc)$ and PBS ( $\boldsymbol{\square})$ containing antibiotic alone or in combination with nisin. (b) C.f.u. of Lact. lactis from homogenized G. mellonella insects following infection in the presence and absence of LLO production (five replicates for each treatment) at different time points during infection. Data shown are representative of three independent experiments. $\mathbf{\square}$, LLO-induced; $\bullet$, empty vector; $\bigcirc$, constitutive LLO. (c) Haemocyte viability assays performed $24 \mathrm{~h}$ after infection with Lact. lactis wild-type and Lact. lactis containing plasmids harbouring inducible LLO or constitutively produced LLO, as well as the empty plasmid. Three individual insects were examined per treatment and the experiment was replicated three times independently. Bars in (a) and (c) indicate SEM. attributed to listeriosis in humans and mice. The progress of infection of G. mellonella by Listeria is accompanied by an increase in pigmentation (Fig. 5a), usually indicative of pro-phenoloxidase (PPO) induction causing melanization (Kanost et al., 2004). In order to determine if the PPO cascade is induced in insects in response to L. monocytogenes infection we examined the level of PO produced by G. mellonella plasma throughout the course of an infection. PO production was detected as described above from plasma isolated from insects at 1, 2, 4, 7 and $24 \mathrm{~h}$ post-inoculation with either PBS or L. monocytogenes strain EGDe (Fig. 5b). Throughout the course of the assay, the level of PO in PBS-infected insects remained constant at $\mathrm{OD}_{490} 0.22$. The presence of $L$. monocytogenes had no effect on PO levels for the first $2 \mathrm{~h}$ of infection (levels of $\mathrm{OD}_{490}$ 0.2 ). By $4 \mathrm{~h}$, the level of PO detected had doubled (to $\mathrm{OD}_{490}$ 0.4) in infected insects and continued to increase to $\mathrm{OD}_{490} 1.2$ at $24 \mathrm{~h}$, indicating that the presence of $L$. moncytogenes induces the PPO cascade in insects.

The insect innate immune system functions at both the cellular and the humoral level. To determine the effects of $L$. monocytogenes at the cellular level, insects were infected with
L. monocytogenes wild-type or mutant strains and the effect on insect haemocytes was examined at $24 \mathrm{~h}$ post-infection as described above. Infection of insects with wild-type $L$. monocytogenes EGDe resulted in a $90 \%$ decrease in numbers of viable haemocytes compared with those injected with PBS alone (Fig. $5 \mathrm{c}$ and d). This phenomenon was also apparent when insects were infected at $30{ }^{\circ} \mathrm{C}$ (Supplementary Fig. S1). In insects infected with L. monocytogenes mutants, the effect upon haemocyte numbers varied according to the nature of the mutation. Insects infected with highly attenuated hly mutants demonstrated only a moderate decrease in haemocyte numbers (a drop of $10-20 \%$ at $24 \mathrm{~h}$ post-infection). Insects infected with the PrfA mutant strain elicited a drop of $57 \%$ in viable haemocytes. These data implicate L. monocytogenes in the destruction of the insect haemocytes, which is followed by insect death. Insects infected with strains that are attenuated for virulence in the insect model (mutated in PrfA or Hly) maintained a high level of haemocyte viability. Therefore, we postulate that insect death is directly linked to haemocyte destruction in G. mellonella.

To further analyse the pathogen-host interaction in the insect model, we followed the interaction between insect 

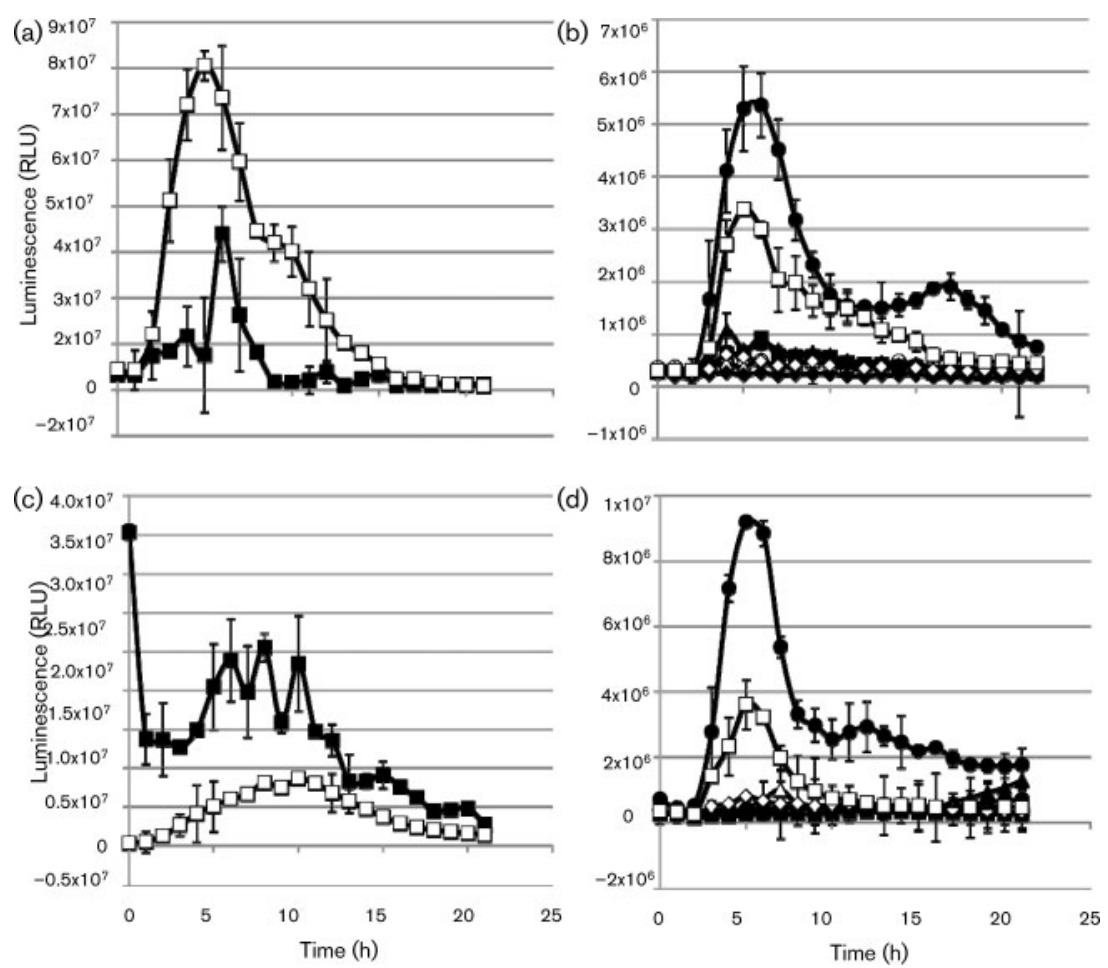

Fig. 4. Real-time monitoring of gene expression using virulence gene promoter fusions to the lux operon in L. monocytogenes during infection in G. mellonella. Promoter expression was monitored by the production of light at $37{ }^{\circ} \mathrm{C}$ (a and b) and at $30{ }^{\circ} \mathrm{C}$ (c and d). (a and c) Promoter activity for $\mathrm{P}_{\text {help }}(\boldsymbol{\square})$ and $\mathrm{P}_{\text {hly }}(\square)$ at the relevant temperature. ( $b$ and $d$ ) Promoter activity for $\mathrm{P}_{\text {prfa }}(\bigcirc), \mathrm{P}_{m p l}(\bullet), \mathrm{P}_{\mathrm{p} 60}(\triangle)$, no promoter $(\boldsymbol{\diamond}), \mathrm{P}_{i n / A}(\boldsymbol{\square}), \mathrm{P}_{h p t}(\boldsymbol{\Delta}), \mathrm{P}_{p / c A}(\diamond)$ and $P_{\text {act } A}(\square)$ at the relevant temperature. Experiments were performed independently in triplicate. Error bars indicate SEM.

haemocytes and Listeria species and mutant strains throughout the course of infection using confocal microscopy. Bacteria were CFSE-stained and used to infect insects as described in Methods. At 1, 2, 4, 7 and $24 \mathrm{~h}$ post-infection, haemolymph was isolated from insects, mounted and stained and then examined by confocal microscopy (Fig. 6). Differential staining and imaging showed that within $1 \mathrm{~h}$ of infection, the majority of $L$.
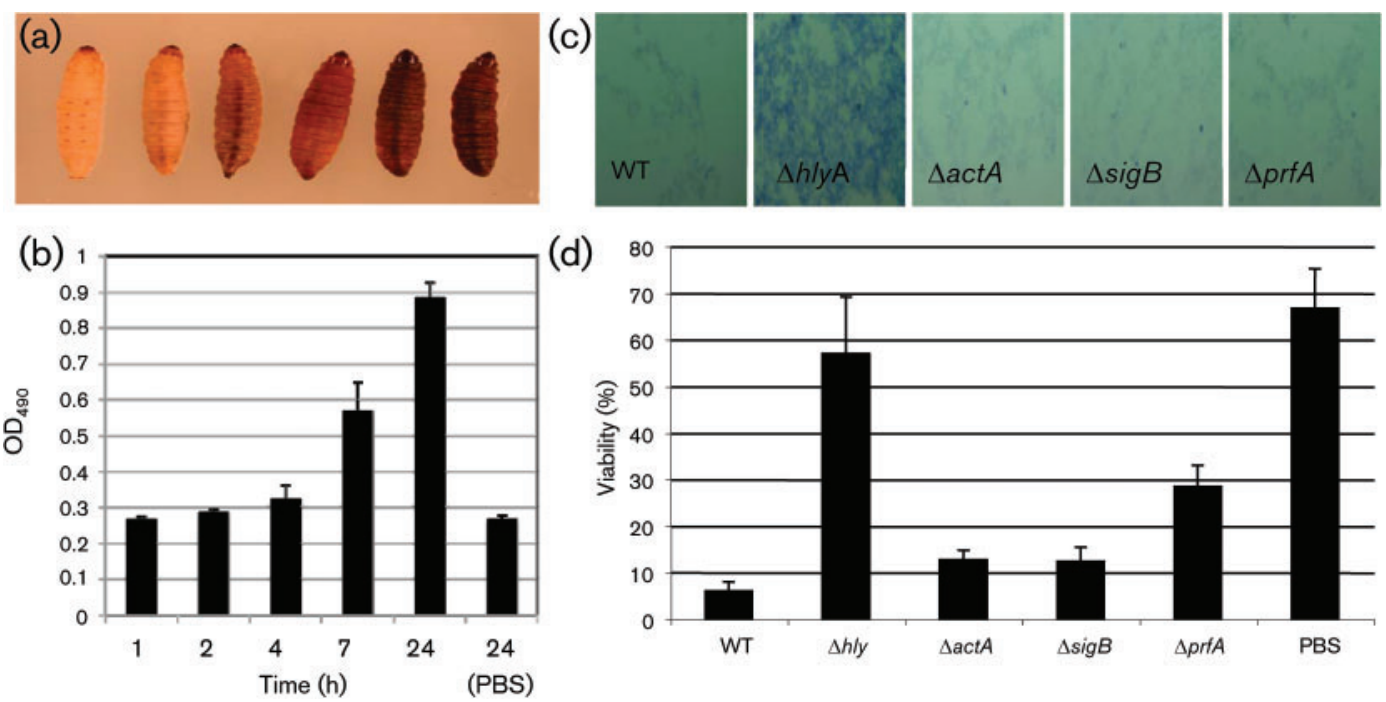

(d)

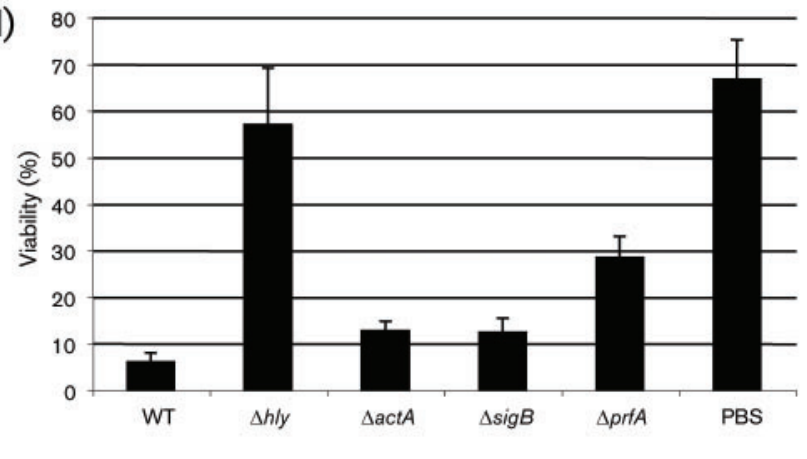

Fig. 5. G. mellonella response to the presence of Listeria. (a) The progress of infection by L. monocytogenes EGDe over the $24 \mathrm{~h}$ after infection in G. mellonella. Images are from $0 \mathrm{~h}$ to $24 \mathrm{~h}$ at $5 \mathrm{~h}$ intervals, from left to right. (b) PPO production in response to the presence of L. monocytogenes EGDe by G. mellonella insects over $24 \mathrm{~h}$ until insect mortality occurs. The level of PPO remained constant throughout the assay when injected with PBS (data shown for PBS is at $24 \mathrm{~h}$ ). Assays were conducted three times independently. Bars indicate SD. (c) G. mellonella haemocyte viability recorded $24 \mathrm{~h}$ after infection with L. monocytogenes EGDe and mutant strains. Visual representation of live haemocytes stained with $2.0 \%$ trypan blue. (d) The number of live haemocytes assessed using a Countess viability counter. Three representatives were taken for each variant; error bars show SD. 


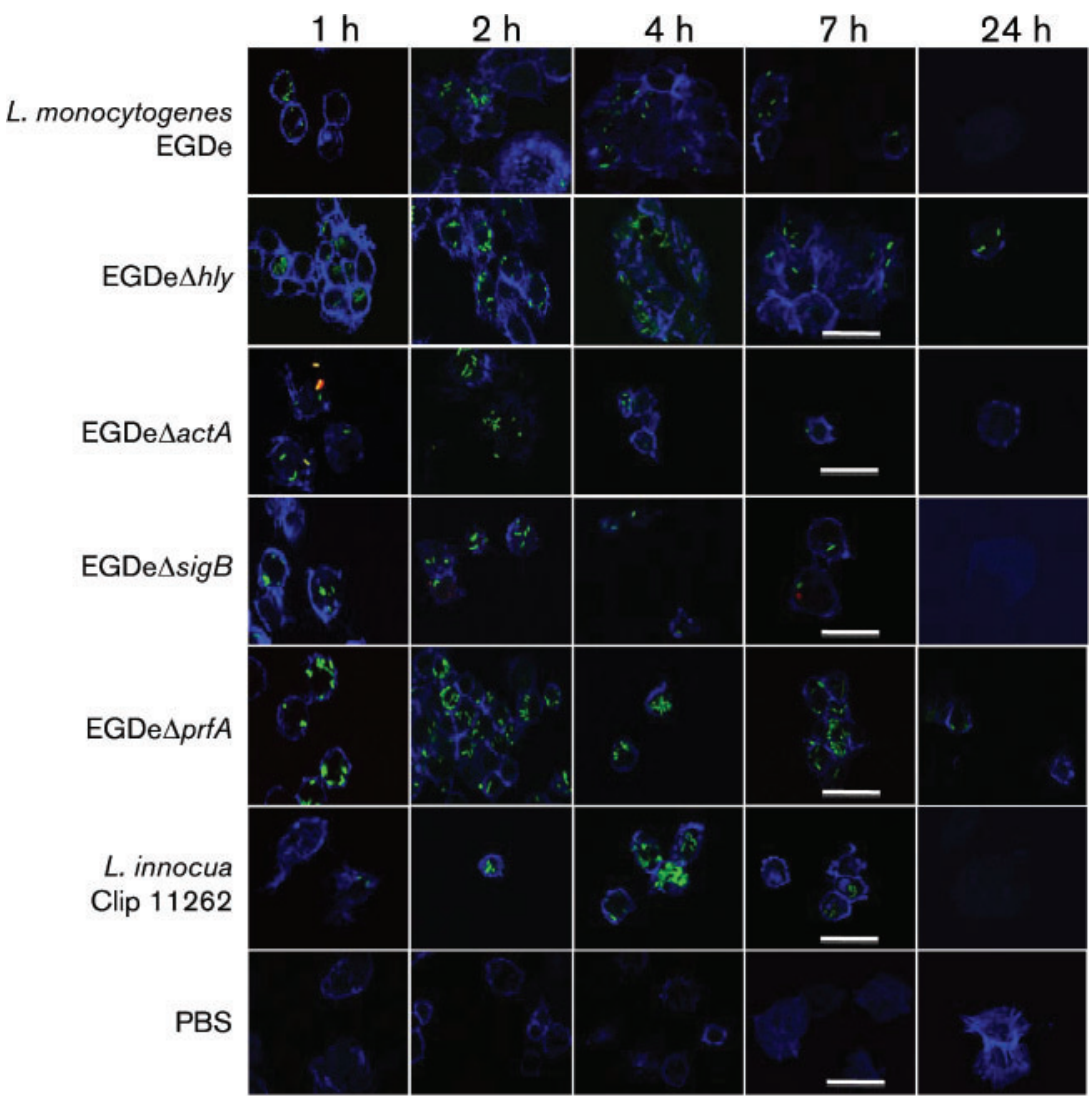

Fig. 6. G. mellonella response to the presence of Listeria. Visualization of L. monocytogenes and $L$. innocua in G. mellonella insects over $24 \mathrm{~h}$ using differential staining and confocal microscopy at the following wavelengths: $488 \mathrm{~nm}$ for CFSE-stained bacteria (green), 543-550 nm for rhodamine-phalloidin (blue), which stains any region producing actin, and 543-550 nm for streptavidin-allophycocyanin to detect non-internalized cells (red). Five individual insects for each strain were examined at each time point during the infectious process. Bars, $30 \mu \mathrm{m}$.

innocua and wild-type and mutant L. monocytogenes strains are intracellularly localized. In the case of the ActA mutant, some bacteria were present on the surface of the cell (stained red) although the majority are intracellular. We found no evidence for actin-based motility irrespective of the time at which samples were taken and of the strain examined. All strains appeared intracellular at $2 \mathrm{~h}$ postinfection with nodule formation evident in each case. By $4 \mathrm{~h}$ post-infection both nodule formation and cell size were reduced, where infection occurred with the ActA, SigB and PrfA mutant strains and with L. innocua when compared with PBS-injected control cells. Seven hours post-infection, bacterial numbers in haemocytes appeared severely reduced for all infections. Twenty-four hours postinfection, nodules were completely absent for all bacterial infections. Furthermore, in infections with wild-type and act $A$ and $\operatorname{sig} B$ L. monocytogenes mutants and for L. innocua, haemocyte numbers were significantly reduced due to either migration of the nodules to the fat body or haemocyte destruction. However, viable haemocytes containing low bacterial numbers were evident in insects infected with the prfA and hly mutants; no haemocytes containing bacteria were observed for wild-type L. monocytogenes (Fig. 5c and d).

The innate immune cellular response in insects is accompanied by secretion of antimicrobial peptides (AMPs) in response to either injury or invasion by a pathogen. Since haemocyte destruction accompanies listerial infection we investigated whether $G$. mellonella mounts an immune response to the presence of $L$. monocytogenes EGDe via the production of AMPs and other factors. We isolated insect fat bodies to examine their production at $7 \mathrm{~h}$ post-infection for the following reasons: bacterial growth in insects is optimal (Fig. 2b), virulence gene expression is maximal (Fig. 4a and b), the PPO cascade had been activated (Fig. 5b) and nodulation of insect cells was evident (Fig. 6). RT-PCR showed that the following genes of the immune response are activated in the presence of L. monocytogenes EGDe: gallerimycin, PPO subunit 2, galliomycin, inducible metalloproteinase inhibitor, gloverin, transferrin and peptidoglycan recognition protein $\mathrm{B}$. The expression of $\beta$-actin was used as an internal control (Supplementary Fig. S2). The control inoculation of PBS alone elicited no AMP response (Supplementary Fig. S2).

\section{DISCUSSION}

The greater wax moth (G. mellonella) has been developed as an infection model for a number of human pathogens (Aperis et al., 2007; Jander et al., 2000; Kavanagh \& Reeves, 2004). This insect species has an active phagocytic cell system within the haemolymph that is capable of defence against infecting bacteria. We, and others, have shown that the larvae are capable of resisting inoculation with non-pathogenic bacterial species (non-pathogenic E. coli, Bifidobacterium spp. and Lact. lactis) (this work and Mylonakis et al., 2005). 
However, infection with specific pathogens results in a fulminant overwhelming infection that causes death of the insect despite the induction of an innate immune response (Kurz \& Ewbank, 2007). The system therefore provides a model with which to study host-pathogen interactions and cellular infection in the presence of innate immunity. Unlike other alternative infection models $(D$. melanogaster and $C$. elegans) G. mellonella can be incubated at $37^{\circ} \mathrm{C}$ and therefore permits the analysis of human pathogens that preferentially express specific virulence factors at this temperature. Other significant benefits of this model include the relatively low cost of the insect larvae and the ease of infection, which allows for their use in relatively high-throughput molecular screening studies.

Our study and a parallel study by Mukherjee et al. (2010) examined infection of G. mellonella by Listeria species and collectively we show that $L$. monocytogenes causes an active pathogenic infection in G. mellonella larvae which is dependent upon intact virulence factor expression. We extend the work of Mukherjee et al. (2010) here by demonstrating high levels of virulence gene expression by L. monocytogenes in situ in infected insects and by showing that the haemolytic factor LLO is sufficient to cause insect death. Insect death is concomitant with a significant reduction in haemocyte numbers in the insect and is preceded by induction of an immune response to invading L. monocytogenes.

We demonstrate similar infectivity for wild-type $L$. monocytogenes in insects compared with the work of Mukherjee et al. (2010). However, whilst Mukherjee and coworkers found that the non-pathogenic L. innocua is lethal for insects only at high infectious doses, we show lethality at lower infectious doses. This difference in susceptibility may be attributed to the fact that, in contrast with laboratory-reared G. mellonella, our out-sourced insects are maintained on an antibiotic-supplemented diet and therefore remain virtually unchallenged by microbes until exposure in our experiments. Indeed, Mukherjee et al. (2010) demonstrate that pre-exposure of G. mellonella to LPS enhances resistance to Listeria infection. In our study, other non-pathogenic bacteria (non-pathogenic E. coli, Bifidobacterium spp. and Lact. lactis) were incapable of causing insect death, suggesting that $L$. innocua possesses a specific mechanism of disease causation in the insect. Significantly, a variety of independent studies have shown that $L$. innосиа is lethal in other non-mammalian model host systems [including Zebrafish embryos (Danio rerio), the nematode C. elegans and the fruit fly D. melanogaster] (Levraud et al., 2009; Mansfield et al., 2003; Thomsen et al., 2006). L. monocytogenes and L. innocua are highly related and through evolutionary adaptation L. innocua has lost the genes encoding major virulence factors (including LLO), rendering this species non-pathogenic in mammalian hosts (Buchrieser et al., 2003). However, LLO mutants in L. monocytogenes are completely attenuated in the G. mellonella infection model (this study; Mukherjee et al., 2010). This implies that $L$. innocua possesses a specific mechanism for inducing insect mortality that is not active in L. monocytogenes. This capacity could be a result of minor genetic variations that exist between these species or it could reside within the 149 genes that are present in $L$. innocua but are absent from L. monocytogenes (Buchrieser et al., 2003; Glaser et al., 2001). We suggest that this separate capacity has been retained in the genome of $L$. innocua (or has been acquired) and allows some advantage in soil or saprophytic environments. The fact that $L$. innocua infects insects using a mechanism distinct from that of L. monocytogenes does not detract from the usefulness of G. mellonella as a model system for the study of L. monocytogenes pathogenesis.

In order to further investigate the role of LLO in this model host, we infected insects with Lact. lactis strains expressing plasmid-encoded LLO. Whilst wild-type Lact. lactis was nonpathogenic in insects, the engineered strains expressing LLO were capable of causing insect death. LLO did not facilitate growth of the Lact. lactis strain in vivo reflecting previous reports that other factors are required to support intracellular growth of non-pathogenic bacteria (Bahey-El-Din et al., 2008; Goetz et al., 2001). Instead, it is likely that LLO produced in situ is directly cytotoxic for insects as shown by the ability of Lact. lactis secreting LLO to reduce haemocyte numbers in vivo. LLO is not toxic for mammalian cells due to the presence of a PEST sequence that targets the protein for ubiquitination and proteolytic degradation in the cytoplasm of infected cells (Decatur \& Portnoy, 2000). It is possible that the LLO PEST sequence does not function in the same manner in insect cells and that the LLO protein is poorly degraded during insect infection. When we followed the growth of L. monocytogenes and the isogenic hly mutant in insects it was clear that LLO contributes to growth of $L$. monocytogenes in the host. Most likely this reflects a defect in access to the cell cytoplasm as clearly demonstrated in the murine model (Hamon et al., 2006; Portnoy et al., 1988). The data therefore suggest that this virulence factor may have a dual effect during the pathogenesis of L. monocytogenes in insects, both in permitting listerial growth and as a toxic factor that is directly lethal for insects when bacterial numbers are elevated.

We have recently developed bioluminescence imaging tools for the analysis of Listeria species in complex environments (Bron et al., 2006; Riedel et al., 2007, 2009; Sleator et al., 2009). Here we utilized constitutive lux expression (mediated by the $\mathrm{P}_{\text {help }}$ promoter) to analyse the growth kinetics of L. monocytogenes in the insect host. To our knowledge, this is the first use of in vivo bioluminescence imaging to monitor host-pathogen (non-commensal) interactions in an insect host in real time and our data suggest that this approach may be amenable to future highthroughput studies or molecular screens. L. monocytogenes was capable of replication following injection but not following oral gavage in insects, demonstrating that the pathogen cannot cause infection by this route and supporting a previous study investigating oral gavage of L. monocytogenes in insects (Fedhila et al., 2010). 
We utilized promoter fusions to lux to analyse listerial gene expression profiles in situ during infection of the insect host. Whilst expression from the hly promoter was undetectable prior to infection, we demonstrated rapid induction of gene expression following infection of insect larvae. Levels of hly gene expression were 100 -fold greater than those seen in vitro in BHI containing activated charcoal (Riedel et al., 2009) and therefore reflect recent transcriptional (array) analyses that showed up to 118-fold induction of hly during infection of murine spleens (Camejo et al., 2009). In our study, the greatest levels of expression were seen from the hly promoter at $37^{\circ} \mathrm{C}$; however, this gene was also expressed when insects were incubated at $30{ }^{\circ} \mathrm{C}$. In addition, other PrfA-dependent promoters $\left(\mathrm{P}_{m p l}\right.$ and $\left.\mathrm{P}_{a c t A}\right)$ were also clearly induced upon infection of the insect host, again reflecting high levels of induction seen during murine infections (Camejo et al., 2009). Interestingly, the PrfA- and SigB-dependent gene inlA was not upregulated in the insect model in contrast with the mammalian infection model (Camejo et al., 2009). The significance of this finding is currently not clear. However, the data demonstrate that L. monocytogenes virulence gene expression profiles are generally similar during infection of both mammalian and non-mammalian hosts. The work also strongly supports previous studies which demonstrate that regulation of specific virulence factors is induced strongly by the in vivo (cellular) environment (Bubert et al., 1999; Chatterjee et al., 2006; Joseph et al., 2006), a process which we show is active even at $30{ }^{\circ} \mathrm{C}$.

An obvious phenotype associated with infection of $G$. mellonella by L. monocytogenes is a visual colour change indicative of induction of the PPO system, a process triggered by microbial peptides and which itself induces tissue damage. We show that the PPO system becomes activated within $4 \mathrm{~h}$ post-infection and remains activated over a $24 \mathrm{~h}$ period. Induction of this system is required to induce phagocytosis by granular cells, although mainly plasmatocytes and granulocytes participate in this process, leading to nodule formation and then melanization and ultimately leading to cell destruction (Bidla et al., 2009). We also confirm the production of other AMPs as demonstrated by Mukherjee et al. (2010). When we examined haemolymph from infected insects, it was apparent that haemocyte numbers are significantly lower in Listeria-infected larvae. The same drop in haemocyte numbers does not occur in insects infected with highly attenuated mutants of $L$. monocytogenes, suggesting that the loss of haemocytes is a direct result of pathogenesis. We postulate that loss of haemocytes may be linked to the death of the insect and is driven by LLO expression. Further work is necessary to demonstrate the mechanisms by which LLO may be toxic to insects in vivo.

In conclusion, we have examined the molecular pathogenesis of L. monocytogenes infection in the alternative $G$. mellonella model system. The work extends a recent independent study by Mukherjee et al. (2010). Both studies demonstrate active infection by $L$. monocytogenes in this model which leads to intracellular growth of the pathogen and is dependent upon production of intact virulence factors. Here, we also show that L. monocytogenes responds to infection of the insect host by significant induction of virulence gene expression and that production of LLO alone is sufficient to kill insect larvae. In addition, we have determined that in our model, L. innocua is pathogenic for insects, utilizing a mechanism that reduces haemocyte viability. Collectively, the data suggest commonalities in the responses of L. monocytogenes to evolutionarily distinct host environments. The work is consistent with a theory that Listeria species evolved to take advantage of saprophytic environments where predatory amoeba (and insects) may represent potential hosts (Akya et al., 2009b).

\section{ACKNOWLEDGEMENTS}

This research was funded by a Marie Curie Host Fellowship for the Transfer of Knowledge. We thank members of the TRAMWAYS Programme - Professor Fergal O'Gara, Professor Alan Dobson and Dr John Morrissey - for active discussions. We also thank Dr Marlies Mooij for helpful suggestions. We thank Professor Pascale Cossart for the gift of L. innocua Clip 11262 and L. monocytogenes mutants in $a c t A$ and $h l y$. Thanks to Catherine Easom and Suzanne Crotty for help with confocal microscopy, to Susan Lapthorne for advice on differential staining and to Dr David Clarke for critical reading of this manuscript.

\section{REFERENCES}

Akya, A., Pointon, A. \& Thomas, C. (2009a). Viability of Listeria monocytogenes in co-culture with Acanthamoeba spp. FEMS Microbiol Ecol 70, 20-29.

Akya, A., Pointon, A. \& Thomas, C. (2009b). Mechanism involved in phagocytosis and killing of Listeria monocytogenes by Acanthamoeba polyphaga. Parasitol Res 105, 1375-1383.

Aperis, G., Fuchs, B. B., Anderson, C. A., Warner, J. E., Calderwood, S. B. \& Mylonakis, E. (2007). Galleria mellonella as a model host to study infection by the Francisella tularensis live vaccine strain. Microbes Infect 9, 729-734.

Bahey-El-Din, M., Casey, P. G., Griffin, B. T. \& Gahan, C. G. (2008). Lactococcus lactis-expressing listeriolysin O (LLO) provides protection and specific $\mathrm{CD}^{+} \mathrm{T}$ cells against Listeria monocytogenes in the murine infection model. Vaccine 26, 5304-5314.

Bergin, D., Murphy, L., Keenan, J., Clynes, M. \& Kavanagh, K. (2006). Pre-exposure to yeast protects larvae of Galleria mellonella from a subsequent lethal infection by Candida albicans and is mediated by the increased expression of antimicrobial peptides. Microbes Infect $\mathbf{8}$, 2105-2112.

Bidla, G., Hauling, T., Dushay, M. S. \& Theopold, U. (2009). Activation of insect phenoloxidase after injury: endogenous versus foreign elicitors. J Innate Immun 1, 301-308.

Bron, P. A., Monk, I. R., Corr, S. C., Hill, C. \& Gahan, C. G. (2006). Novel luciferase reporter system for in vitro and organ-specific monitoring of differential gene expression in Listeria monocytogenes. Appl Environ Microbiol 72, 2876-2884.

Bubert, A., Sokolovic, Z., Chun, S. K., Papatheodorou, L., Simm, A. \& Goebel, W. (1999). Differential expression of Listeria monocytogenes 
virulence genes in mammalian host cells. Mol Gen Genet 261, 323 336.

Buchrieser, C., Rusniok, C., Kunst, F., Cossart, P. \& Glaser, P. (2003). Comparison of the genome sequences of Listeria monocytogenes and Listeria innocua: clues for evolution and pathogenicity. FEMS Immunol Med Microbiol 35, 207-213.

Camejo, A., Buchrieser, C., Couve, E., Carvalho, F., Reis, O., Ferreira, P., Sousa, S., Cossart, P. \& Cabanes, D. (2009). In vivo transcriptional profiling of Listeria monocytogenes and mutagenesis identify new virulence factors involved in infection. PLoS Pathog $\mathbf{5}$, e1000449.

Chakraborty, T., Leimeister-Wachter, M., Domann, E., Hartl, M., Goebel, W., Nichterlein, T. \& Notermans, S. (1992). Coordinate regulation of virulence genes in Listeria monocytogenes requires the product of the prfA gene. J Bacteriol 174, 568-574.

Chatterjee, S. S., Hossain, H., Otten, S., Kuenne, C., Kuchmina, K., Machata, S., Domann, E., Chakraborty, T. \& Hain, T. (2006). Intracellular gene expression profile of Listeria monocytogenes. Infect Immun 74, 1323-1338.

Cheng, L. W. \& Portnoy, D. A. (2003). Drosophila S2 cells: an alternative infection model for Listeria monocytogenes. Cell Microbiol 5, 875-885.

Decatur, A. L. \& Portnoy, D. A. (2000). A PEST-like sequence in listeriolysin $\mathrm{O}$ essential for Listeria monocytogenes pathogenicity. Science 290, 992-995.

Disson, O., Grayo, S., Huillet, E., Nikitas, G., Langa-Vives, F. Dussurget, O., Ragon, M., Le Monnier, A., Babinet, C. \& other authors (2008). Conjugated action of two species-specific invasion proteins for fetoplacental listeriosis. Nature 455, 1114-1118.

Disson, O., Nikitas, G., Grayo, S., Dussurget, O., Cossart, P. \& Lecuit, M. (2009). Modeling human listeriosis in natural and genetically engineered animals. Nat Protoc 4, 799-810.

Eleftherianos, I., Marokhazi, J., Millichap, P. J., Hodgkinson, A. J., Sriboonlert, A., ffrench-Constant, R. H. \& Reynolds, S. E. (2006). Prior infection of Manduca sexta with non-pathogenic Escherichia coli elicits immunity to pathogenic Photorhabdus luminescens: roles of immune-related proteins shown by RNA interference. Insect Biochem Mol Biol 36, 517-525.

Ermolaeva, S., Novella, S., Vega, Y., Ripio, M. T., Scortti, M. \& Vazquez-Boland, J. A. (2004). Negative control of Listeria monocytogenes virulence genes by a diffusible autorepressor. Mol Microbiol 52, 601-611.

Fedhila, S., Buisson, C., Dussurget, O., Serror, P., Glomski, I. J., Liehl, P., Lereclus, D. \& Nielsen-LeRoux, C. (2010). Comparative analysis of the virulence of invertebrate and mammalian pathogenic bacteria in the oral insect infection model Galleria mellonella. J Invertebr Pathol 103, 24-29.

Freitag, N. E., Port, G. C. \& Miner, M. D. (2009). Listeria monocytogenes - from saprophyte to intracellular pathogen. Nat Rev Microbiol 7, 623-628.

Garner, M. R., Njaa, B. L., Wiedmann, M. \& Boor, K. J. (2006). Sigma B contributes to Listeria monocytogenes gastrointestinal infection but not to systemic spread in the guinea pig infection model. Infect Immun 74, 876-886.

Glaser, P., Frangeul, L., Buchrieser, C., Rusniok, C., Amend, A., Baquero, F., Berche, P., Bloecker, H., Brandt, P. \& other authors (2001). Comparative genomics of Listeria species. Science 294, 849852.

Goetz, M., Bubert, A., Wang, G., Chico-Calero, I., Vazquez-Boland, J. A., Beck, M., Slaghuis, J., Szalay, A. A. \& Goebel, W. (2001). Microinjection and growth of bacteria in the cytosol of mammalian host cells. Proc Natl Acad Sci U S A 98, 12221-12226.
Greene, S. L. \& Freitag, N. E. (2003). Negative regulation of PrfA, the key activator of Listeria monocytogenes virulence gene expression, is dispensable for bacterial pathogenesis. Microbiology 149, 111-120.

Hamon, M., Bierne, H. \& Cossart, P. (2006). Listeria monocytogenes: a multifaceted model. Nat Rev Microbiol 4, 423-434.

Jander, G., Rahme, L. G. \& Ausubel, F. M. (2000). Positive correlation between virulence of Pseudomonas aeruginosa mutants in mice and insects. J Bacteriol 182, 3843-3845.

Joseph, B., Przybilla, K., Stuhler, C., Schauer, K., Slaghuis, J., Fuchs, T. M. \& Goebel, W. (2006). Identification of Listeria monocytogenes genes contributing to intracellular replication by expression profiling and mutant screening. J Bacteriol 188, 556-568.

Kanost, M. R., Jiang, H. \& Yu, X. Q. (2004). Innate immune responses of a lepidopteran insect, Manduca sexta. Immunol Rev 198, 97-105.

Karrer, F. M., Reitz, B. L., Hao, L. \& Lafferty, K. J. (1992). Fluorescein labeling of murine hepatocytes for identification after intrahepatic transplantation. Transplant Proc 24, 2820-2821.

Kavanagh, K. \& Reeves, E. P. (2004). Exploiting the potential of insects for in vivo pathogenicity testing of microbial pathogens. FEMS Microbiol Rev 28, 101-112.

Kurz, C. L. \& Ewbank, J. J. (2007). Infection in a dish: highthroughput analyses of bacterial pathogenesis. Curr Opin Microbiol 10, $10-16$

Lecuit, M. (2007). Human listeriosis and animal models. Microbes Infect 9, 1216-1225.

Levraud, J. P., Disson, O., Kissa, K., Bonne, I., Cossart, P., Herbomel, P. \& Lecuit, M. (2009). Real-time observation of Listeria monocytogenesphagocyte interactions in living zebrafish larvae. Infect Immun 77, 36513660 .

Mansfield, B. E., Dionne, M. S., Schneider, D. S. \& Freitag, N. E. (2003). Exploration of host-pathogen interactions using Listeria monocytogenes and Drosophila melanogaster. Cell Microbiol 5, 901-911.

McGann, P., Ivanek, R., Wiedmann, M. \& Boor, K. J. (2007). Temperature-dependent expression of Listeria monocytogenes internalin and internalin-like genes suggests functional diversity of these proteins among the listeriae. Appl Environ Microbiol 73, 2806-2814.

Mukherjee, K., Altincicek, B., Hain, T., Domann, E., Vilcinskas, A. \& Chakraborty, T. (2010). Galleria mellonella as a model system for studying Listeria pathogenesis. Appl Environ Microbiol 76, 310-317.

Mylonakis, E., Moreno, R., El Khoury, J. B., Idnurm, A., Heitman, J., Calderwood, S. B., Ausubel, F. M. \& Diener, A. (2005). Galleria mellonella as a model system to study Cryptococcus neoformans pathogenesis. Infect Immun 73, 3842-3850.

Nadon, C. A., Bowen, B. M., Wiedmann, M. \& Boor, K. J. (2002). Sigma $\mathrm{B}$ contributes to PrfA-mediated virulence in Listeria monocytogenes. Infect Immun 70, 3948-3952.

Peel, M., Donachie, W. \& Shaw, A. (1988). Temperature-dependent expression of flagella of Listeria monocytogenes studied by electron microscopy, SDS-PAGE and Western blotting. J Gen Microbiol 134, 2171-2178.

Portnoy, D. A., Jacks, P. S. \& Hinrichs, D. J. (1988). Role of hemolysin for the intracellular growth of Listeria monocytogenes. J Exp Med 167, 1459-1471.

Riedel, C. U., Monk, I. R., Casey, P. G., Morrissey, D., O'Sullivan, G. C., Tangney, M., Hill, C. \& Gahan, C. G. (2007). Improved luciferase tagging system for Listeria monocytogenes allows real-time monitoring in vivo and in vitro. Appl Environ Microbiol 73, 3091-3094.

Riedel, C. U., Monk, I. R., Casey, P. G., Waidmann, M. S., Gahan, C. G. \& Hill, C. (2009). AgrD-dependent quorum sensing affects biofilm formation, invasion, virulence and global gene expression profiles in Listeria monocytogenes. Mol Microbiol 71, 1177-1189. 
Sheehan, B., Klarsfeld, A., Msadek, T. \& Cossart, P. (1995). Differential activation of virulence gene expression by PrfA, the Listeria monocytogenes virulence regulator. J Bacteriol 177, 6469-6476.

Sleator, R. D., Watson, D., Hill, C. \& Gahan, C. G. (2009). The interaction between Listeria monocytogenes and the host gastrointestinal tract. Microbiology 155, 2463-2475.

Thomsen, L. E., Slutz, S. S., Tan, M. W. \& Ingmer, H. (2006). Caenorhabditis elegans is a model host for Listeria monocytogenes. Appl Environ Microbiol 72, 1700-1701.
Wilson, R. L., Tvinnereim, A. R., Jones, B. D. \& Harty, J. T. (2001). Identification of Listeria monocytogenes in vivo-induced genes by fluorescence-activated cell sorting. Infect Immun 69, 5016-5024.

Yano, T., Mita, S., Ohmori, H., Oshima, Y., Fujimoto, Y., Ueda, R., Takada, H., Goldman, W. E., Fukase, K. V. \& other authors (2008). Autophagic control of Listeria through intracellular innate immune recognition in Drosophila. Nat Immunol 9, 908-916.

Edited by: H. Ingmer 